\title{
The Influence of Customer Familiarity and Personal Innovativeness toward Information Technologies on the Sense of Virtual Community and Participation
}

\author{
Manuel J. Sánchez-Franco ${ }^{1, *}$, José Antonio Carballar-Falcón ${ }^{1}$, \\ Francisco J. Martínez-López ${ }^{2}$, and Juan Carlos Gázquez-Abad ${ }^{3}$ \\ ${ }^{1}$ University of Sevilla, Ramón y Cajal 1, \\ E-41018 Sevilla, Spain \\ majesus@us.es \\ ${ }^{2}$ University of Granada, Campus Cartuja, s/n, \\ E-18171 Granada, Spain \\ ${ }^{3}$ University of Almería, Ctra. Sacramento s/n, \\ E-04120, Almería, Spain
}

\begin{abstract}
The aim of this study is to investigate, on the one hand, the main effects of personal innovativeness and familiarity on perceived community support in the domain of the social network site Tuenti, and, on the other hand, the moderating effects of personal innovativeness on relationships between familiarity and perceived community support. A Structural Equation Modelling, specifically Partial Least Square, is proposed to assess the relationships between the constructs together with the predictive power of the model analysed. The results demonstrate that increasing PIIT and familiarity can be seen as important initiatives that promote perceived community support and avoid the consideration of competitive social network sites.
\end{abstract}

Keywords: Perceived community support, Social Network Sites, sense of virtual community, familiarity, personal innovativeness, moderating effects.

\section{Introduction}

Social Network Sites (SNSs) are virtual environments that allow users to connect with each other in order to seek and/or share content (e.g., opinions or experiences), professional advancement, friendship, and entertainment. In particular, users have an essential focus on social interaction and mutual support. In this research, SNSs will thus be conceptualised as an online setting that emphasises (a) an individual's feelings of membership, identity, belonging, and attachment to others that is maintained by integration and fulfillment of needs (i.e., a sense of a virtual community), and (b) virtual enduring participation [cf. 10, 35, 44].

Assuming that the ultimate success of SNSs derives from an enduring usage, Bhattacherjee (2001) emphasised the importance of continuance over initial

\footnotetext{
* Coresponding author.
} 
acceptance. Long-term viability of SNSs and their eventual success will indeed depend on their enduring participation rather than situational participation, and, likewise, the formation of social capital - e.g., support seeking and support providing [cf. 16]. Nevertheless, how to maintain and intensify the number of members and posts remains a problem. In fact, if not gratified and involved properly, members lose interest and eventually reduce their level of interaction. Perceived community support [hereinafter, PCS] can, then, be considered as an essential indicator of community success. Assuming that "the study of the community as a relevant source of support has been comparatively lacking" [26, p. 197], the purpose of this research will be to expand previous research of what contributes to PCS.

In particular, this paper is structured as follows. In the next section, we present a research model which connects PCS with two sets of factors: familiarity and personal innovativeness toward Information Technologies (hereinafter, PIIT). That is to say, identifying main determinants of PCS are the goals of this study. We will investigate the roles of familiarity and PIIT in building PCS. These two factors have not been examined in previous research on PCS. The hypothesised model will be validated empirically using data from a field survey of the most popular computer-mediated SNS among the Spanish college student population, Tuenti -created in January 2006 by Zaryn Dentzel. This paper will address these questions, and outline the managerial implications, and limitations.

\section{Theory and Research Hypotheses}

Previous research has shown individual differences play an important role in users' decisions to accept or reject innovations [38, 39, 41, 46]. In this regard, we propose two factors that can help identify such drivers of PCS to target those members that are highly enthusiastic during the acceptance of an SNS. The first is a personal trait (i.e., a stable situation-specific individual difference) named personal innovativeness toward Information Technologies (PIIT), and the second is a psychological state (i.e., a dynamic, situation-specific individual difference) named familiarity.

\subsection{Perceived Community Support, PCS}

Blanchard and Markus (2002) argue that "the success of community support platforms depends on the active participation of a significant percentage of the community members". Community participation will herein be conceptualised as community involvement, active participation in community activities, or social interaction [44]; e.g., "I respond to calls to support my Tuenti community". Participation is necessary for enduring interactivity and, consequently, an essential driver of successful SNSs. Secondly, the exchange of mutual support $-c f$. integration and fulfillment of needs- is a very important reason for the existence of virtual communities [4, 42, 49]; i.e. feelings of being supported by others in the community (i.e., community organisation) while also supporting them. In fact, online contacts are perceived to be as helpful as support provided by offline contacts [cf. 34, 48]; e.g., "I could find people that helped me feel better". Thirdly, a main dimension -associated with community support- that distinguishes virtual communities from mere virtual 
groups is mainly their sense of virtual community (or community integration), defined as "as members' feelings of membership, identity, belonging, and attachment to a group that interacts primarily through electronic communication" [7; $c f .8,35]$; e.g., "My affective bonds with my Tuenti community are the main reason why I continue to use its service".

\subsection{Personal Innovativeness toward Information Technologies, PIIT}

Since SNSs represent an innovation, existing innovation theoretical frameworks from the innovation literature may be effectively applied to SNSs -as a new technology service. If users are more willing to accept innovative technologies in general, they may be more accepting of innovative technologies such as SNS, and more predisposed to having a primary focus on social interpersonal communication. Given the relative infancy of SNSs, it will, therefore, be appropriate to test personal innovativeness toward Information Technologies (PIIT) as an influencing variable.

In our research, as Agarwal and Prasad (1998), we shift the focus from observed adoption behaviour to underlying personal trait operating in differing technology acceptance realms. PIIT has a stable influence across situations involving information technology, while Rogers defines innovativeness as a behaviour -in the context of diffusion of innovations. In particular, PIIT is "an important individual trait for examining the acceptance of information technology innovations" [1, p. 206; $c f$. also $24,26,27]$, and it is conceptualised as an individual's willingness to try out an IT, seeking out new, mentally or sensually stimulating experiences. PIIT describes the extent to which the individual has an innate propensity toward adopting a new IT; i.e., a form of openness to change. Innovative individuals will thus be more comfortable and confident when using a new system [cf. 51], this being a function of members' risk tolerance. That is, as Woszczynski et al. (2002, p.381) argued, "users who score high on PIIT may tend to be the first individuals to adopt a new technology product".

Initially we conceptualise and evaluate PIIT as a direct determinant of PCS. Indeed, we expect a positive relationship exists between PIIT and the formation and maintenance of social capital. Highly-innovative members will develop more positive perceptions about SNSs in terms of perceived usefulness and ease of use. In this regard, innovative members realise better the usefulness of SNSs for trying out a SNS and consequently, support seeking and support providing (i.e., community organisation and participation). Rogers (1995) related innovativeness with social participation. Users who adopt innovative ideas more than others will tend to have a stronger desire to participate in and contribute to SNS. PIIT captures a positive dimension of individuals to experiment with SNSs. Likewise, as Chou (2010) confirms, online community members' PIIT is positively related to their perceived identity verification. "For most participants, identity - both the establishment of their own reputation and the recognition of others - plays a vital role" [15, p.30]. Highlyinnovative members have more positive individual feelings of identity and attachment with the others (i.e., community integration), showing a strong link between PIIT and PCS.

To sum up, innovative members will tend to be proactive in accepting SNS and in taking risks, solving a problem or generating an idea through online interactions -as instrumental benefits- or for fun and relaxation -as hedonic benefits- among others 
and predicting stronger feelings of being supported by the SNS. PCS will, therefore, be influenced by stable individual difference such as PIIT. Based on the previous arguments, this research proposes the following hypothesis: PIIT positively influences PCS (i.e., community organisation, Hla; integration, $\mathbf{H 1 b}$; and participation, $\boldsymbol{H} \mathbf{1 c}$ ). See Figure 1.

\subsection{Familiarity}

Familiarity about the functioning of an SNS will be defined here as the number of SNS-related direct or indirect experiences that have been accumulated by members, being considered one of the main drivers explaining their behaviour [cf. 42].

Familiarity is an important internal source of information; i.e., the more familiar the SNS are to members, the less time and effort will be spent on information search. Familiarity is the knowledge of a product class [27] or "a specific activity-based cognizance based on previous experience or learning of how to use the particular interface" [19, p.727]; i.e., role clarity, ability and motivation [30]. Familiarity therefore, gauges the degree to which prior experience has been understood.

Users' familiarity (and knowledge) will affect customer information processing activities in several ways [ $c f .3]$, leading to a more elaborated cognitive structure [ $c f$. 17, 36]. As users use a service more frequently, they are more familiar with it, reducing uncertainty in future decision situations (i.e., perceiving less risk), and simplifying relationships with others by generating a knowledge structure [ $c f$. also 6 , 18, 19]. Familiarised members will believe that they know an SNS well [cf. 3], showing an individual judgment of one's capability to use an SNS (i.e., self-efficacy) and more positive beliefs and attitudes about it. Familiarity could thus be used to describe the extent to which users know about an SNS.

A general principle is the easier the utilisation could be and the lower the entry barrier, the higher the possibility of using it is. Users' satisfaction and familiarity both have positive impacts on their voluntary participation in co-production and contribution to SNS [cf., 23]. Hence, we expect a positive relationship exists between members' familiarity and the formation and maintenance of social capital; that is to say, the familiar virtual settings create a level of comfort such that members feel free to discuss and share their ideas. Increased familiarity among members will promote mutual aid and empathy. When the members are familiar with the others, they tend to be more informal and are more willing to share personal information, thereby (a) achieving greater PCS and (b) resulting in increased opportunities to deepen their knowledge about them [cf. 47]. Likewise, interpersonal interactions increase familiarity between community members, leading to a greater desire to interact in the future. Indeed, previous research supports that the more familiarised members normally exhibit targeted behaviour while the less familiarised opt for general exploration. Less familiarised users tend to engage in community participation but in a limited way, preferring to be readers rather than writers, and being reticent -or very seldom posting. As Casaló et al. (2007, p.6) proposed, "familiarity with a virtual community favours the individual skills in order to interact with other community members and, therefore, the participation in the virtual community may be increased". 
To sum up, to promote PCS online moderators should use strategies to increase familiarity among members of SNS and develop favourable social relationships. Users will show more commitment once they could understand the value, norm and rule of the SNS. "As customers become familiar with an organization and/or its employees, relationships based on trust and reciprocity often develop" [23, p.13]. Based on the previous arguments, this research proposes the following hypothesis: Familiarity positively influences PCS (i.e., community organisation, H2a; integration, $\boldsymbol{H} \mathbf{2 b}$; and participation, $\boldsymbol{H} 2 \boldsymbol{c}$ ). See Figure 1.

Thirdly, members with higher PIIT would require less information than the members with lower PIIT. Innovative members will be highly predisposed toward adopting SNSs, whereas others may prefer to continue exploring familiar communitytools. PIIT could then be a moderator of familiarity. Members with high personal innovativeness may not be familiarised members. Innovative users might be easily persuaded to try the new technology without any elaborated cognitive structure (or familiarity). We will, therefore, develop a third hypothesis maintaining that innovative members will not only hold different belief structures in terms of familiarity, but also that individual innovativeness will moderate the impact of familiarity on PCS. Higher levels of PIIT may diminish factors involving prior online experience (e.g., SNS familiarity), and place more focus on new, mentally or sensually stimulating experiences. PIIT may, therefore, be viewed as a moderating driver affecting the relationship between familiarity and PCS. Based on the previous arguments, this research proposes the following hypothesis: Overall, PIIT moderates (weakens) the relationship between familiarity and PCS (i.e., community organisation, $\boldsymbol{H 3 a}$; integration, $\boldsymbol{H 3} \boldsymbol{b}$; and participation, $\boldsymbol{H 3} \boldsymbol{c})$. See Figure 1.

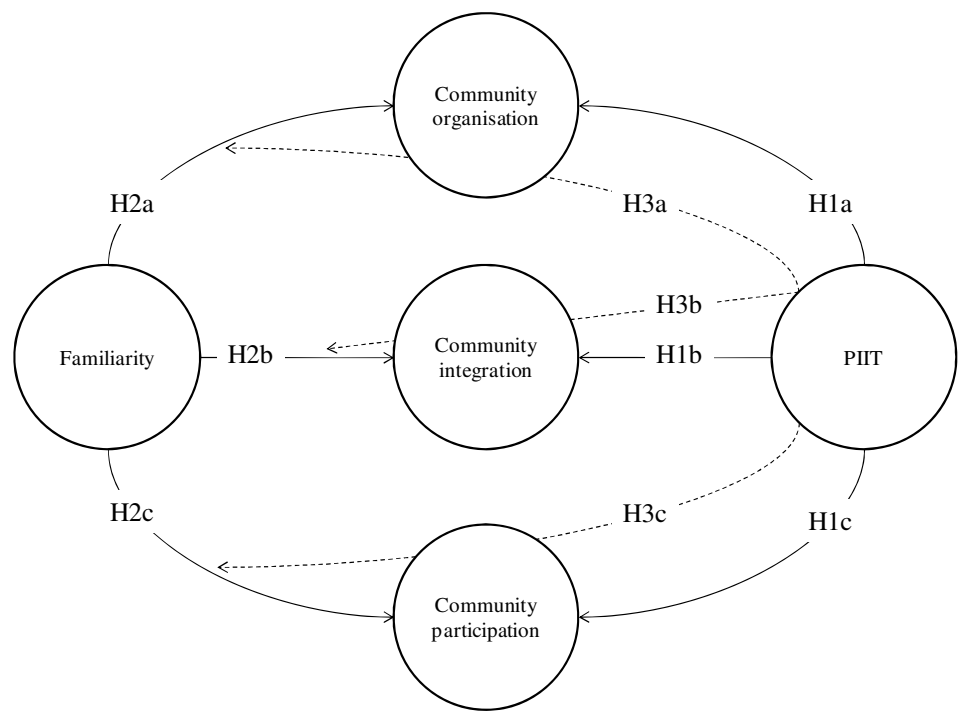

Fig. 1. Research model. Hypotheses. 


\section{Method}

\subsection{Participants}

The structural model was validated empirically using data from a field survey of the most popular computer-mediated SNS among the Spanish college student population, Tuenti. Specifically, participants were recruited from social studies at a public University in Seville (Spain). The exclusion of invalid questionnaires due to duplicate submissions or extensive empty data fields resulted in a final convenience sample of 278 users. $42.8 \%$ were male respondents. The average age was 21.04 (SD: 2.403).

\subsection{Measures}

We have adopted the common latent model perspective, in which the latent variable is understood to be the cause of the indicators (i.e., reflective indicators). Fourteen items were used to assess community participation, organisation and integration (or identification with an SNS) -taken from Herrero and Gracia (2007), Geyskens et al. (1996), Loewenfeld (2006), and Sánchez-Franco (2009). On the other hand, a total of three items were employed to measure familiarity [18]. Finally, the self-report instrument for measuring the degree of PIIT has been operationalised by Agarwal and Prasad (1998) in the form of a four-item questionnaire.

A pretest assessed the suitability of the wording and format, and the extent to which measures represented all facets of constructs. All items are seven-point Likerttype, ranging from «strongly disagree», 1, to «strongly agree», 7.

\subsection{Data Analysis}

The hypotheses testing was conducted using Partial Least Squares (PLS), specifically, SmartPLS 2.0.M3 software [37].

Taking into account that hypotheses $\mathrm{H} 3 \mathrm{abc}$ are based on interaction effects, one well-known technique has had to be applied to test these moderated relationships: product-indicator approach [24].

\section{Evaluation of PLS Path Model Results}

\subsection{Assessing Our Reflective Measurement Model}

Our measurement model proposed causal relationships from the latent variables to the manifest variables in their block. That is, as Henseler et al. (2009, p.285) summarise, "each manifest variable in a certain measurement model is assumed to be generated as a linear function of our latent variables and the residual $\varepsilon$ ".

In particular, the measurement model was evaluated using the full sample (278 individuals) -all items and dimensions- and then the PLS results were used to eliminate possible problematic items. On the one hand, individual reflective-item reliability was assessed by examining the loadings of the items with their respective construct, that is, in terms of correlations between a construct and each of its manifest variables (or standardised loadings). Individual reflective-item reliabilities were over 
the recommended acceptable cut-off level of 0.7. See Table 1. On the other hand, construct reliability was assessed using the composite reliability $(\rho c)$. The composite reliability takes into account that indicator shave different loadings, and can be (a) interpreted in the same way as Cronbach's $\alpha$, and therefore, (b) used to check how well a construct is measured by its assigned indicators. The composite reliabilities for the multiple reflective indicators were well over the recommended acceptable 0.7 level, demonstrating high internal consistency. Moreover, we checked the significance of the loadings with a bootstrap procedure (500 sub-samples) for obtaining t-statistic values. They all are significant. See Table 1.

Finally, convergent validity on the one hand, involves the degree to which individual items reflecting a construct converge in comparison to items measuring different constructs. On the other hand, discriminant validity concerns the degree to which the measures of different constructs differ from one another. Convergent and discriminant validities were, therefore, assessed by stipulating that the square root of the average variance extracted (AVE) from its indicators should be at least 0.7 (i.e., AVE $>0.5$ ) and should be greater than that construct's correlation with other constructs. All latent constructs satisfied these conditions. See Tables 1 and 2.

Table 1. Measurement model. Main effects model.

\begin{tabular}{|c|c|c|c|}
\hline \multicolumn{4}{|c|}{$\begin{array}{l}\text { a. Individual item reliability-individual item loadings. Construct } \\
\text { reliability and convergent validity coefficients }\end{array}$} \\
\hline Latent Dimension & Loadings $^{\mathrm{a}}$ & $\rho_{\mathrm{c}}$ & AVE \\
\hline CO. Community organisation & & 0.9243 & 0.7097 \\
\hline $\begin{array}{l}\text { CO1. I could find people that helped } \\
\text { me feel better }\end{array}$ & 0.8059 & & \\
\hline $\begin{array}{l}\mathrm{CO} 2 . \mathrm{I} \text { could find someone to listen } \\
\text { to me when I felt down }\end{array}$ & 0.8603 & & \\
\hline $\begin{array}{l}\text { CO3. I could find a source of } \\
\text { satisfaction for myself }\end{array}$ & 0.8722 & & \\
\hline $\begin{array}{l}\text { CO4. I could be able to cheer up and } \\
\text { get into a better mood }\end{array}$ & 0.8749 & & \\
\hline $\begin{array}{l}\text { CO5. I could relax and easily forget } \\
\text { my problems }\end{array}$ & 0.7955 & & \\
\hline $\begin{array}{l}\text { CI. Identification with virtual } \\
\text { community (i.e., } \\
\text { integration) }\end{array}$ & 0.8059 & 0.9426 & 0.8042 \\
\hline $\begin{array}{l}\text { CI1. My affective bonds with my } \\
\text { Tuenti community are the main } \\
\text { reason why I continue to use its } \\
\text { service }\end{array}$ & 0.8896 & & \\
\hline $\begin{array}{l}\text { CI2. I enjoy being a member of my } \\
\text { Tuenti community }\end{array}$ & 0.9103 & & \\
\hline $\begin{array}{l}\text { CI3. I have strong feelings for my } \\
\text { Tuenti community }\end{array}$ & 0.8799 & & \\
\hline $\begin{array}{l}\text { CI4. In general, I relate very well to } \\
\text { the members of my Tuenti } \\
\text { community }\end{array}$ & 0.9069 & & \\
\hline
\end{tabular}


Table 1. (continued)

\begin{tabular}{llll} 
CP. Community participation & & 0.9109 & 0.6723 \\
\hline CP1. I participate in order to & 0.8787 & \\
stimulate my Tuenti community & & \\
CP2. I take part actively in activities & 0.7801 & \\
in my Tuenti community & 0.7789 & \\
CP3. I take part in social groups in & & \\
my Tuenti community & & \\
CP4. I respond to calls to support my & 0.7761 & \\
Tuenti community \\
CP5. I take part actively in socio- \\
recreational activities in my Tuenti \\
community
\end{tabular}

FAM1. I am quite familiar with my

Tuenti community

0.9038

FAM2. I am quite familiar with the services offered by my Tuenti 0.9004 community

FAM3. In comparison with the typical user of my Tuenti community, I believe I am quite familiar with it

\begin{tabular}{l} 
PIIT. PIIT \\
PIIT1. If I heard about a new \\
information technology, I would look \\
for ways of experimenting with it \\
PIIT2. Among my peers, I am \\
$\begin{array}{l}\text { usually the first to try out new } \\
\text { information technologies }\end{array}$ \\
$\begin{array}{l}\text { PIIT3. In general, I am hesitant to try } \\
\text { out new information technologies (R) }\end{array}$ \\
$\begin{array}{l}\text { PIIT4. I like to experiment with new } \\
\text { information technologies }\end{array}$ \\
\hline $\begin{array}{l}\text { (R) Reverse item } \\
\text { a All loadings are significant at } p<0.0013\end{array}$ \\
\hline
\end{tabular}

Table 2. Discriminant validity coefficients. Main effects model.

\begin{tabular}{l|c|c|c|c|c}
\hline & CO & CI & CP & FAM & PIIT \\
\hline CO & $\mathbf{0 . 8 4 2 4}$ & & & & \\
CI & 0.3932 & $\mathbf{0 . 8 9 6 8}$ & & & \\
CP & 0.5358 & 0.4248 & $\mathbf{0 . 8 2 0 0}$ & & \\
FAM & 0.5237 & 0.4371 & 0.6326 & $\mathbf{0 . 9 4 0 0}$ & \\
PIIT & 0.1208 & 0.1438 & 0.2996 & 0.1790 & $\mathbf{0 . 9 0 7 0}$ \\
\hline
\end{tabular}

Note: Diagonal elements are the square root of average variance extracted (AVE) between the constructs and their measures. Off-diagonal elements are correlations between constructs 


\subsection{Assessing Our Structural Model}

The bootstrap re-sampling procedure (500 sub-samples) was used to generate the standard errors and the t-values. Firstly, the research model appears to have an appropriate predictive power for endogenous constructs to exceed the required amount of $0.10-\mathrm{R}$-square values. Furthermore, our structural model explains each endogenous latent construct by only two exogenous latent construct. $R^{2}>0.19$ may, therefore, be acceptable [ $c f$. 12]. See Figure 2. A measure of the predictive relevance of dependent variables in the proposed model is the $Q 2$ test. A $Q 2$ value (i.e., only applicable in dependent and reflective constructs) greater than 0 implies that the model offers predictive relevance. The results of our study confirm that the main model offers very satisfactory predictive relevance: community integration $(Q 2=$ $0.1507>0)$, community participation $(Q 2=0.3636>0)$ and community organisation $(Q 2=0.1930>0)$.

The data fully supported the main effects model and the hypotheses (excepting H1a and $\mathrm{H} 1 \mathrm{~b}$ ) are supported on the basis of empirical data. As indicated in the main effects model, PIIT has a significant impact on participation, with path coefficients of $0.192(\mathrm{p}<0.001)$. However, due to the cross-sectional design of this study, no causation can be determined. Likewise, familiarity has a significant impact on organisation, integration and participation with path coefficients of $0.519(\mathrm{p}<0.001)$, $0.425(\mathrm{p}<0.001)$ and $0.598(\mathrm{p}>0.001)$. See Figure 2.

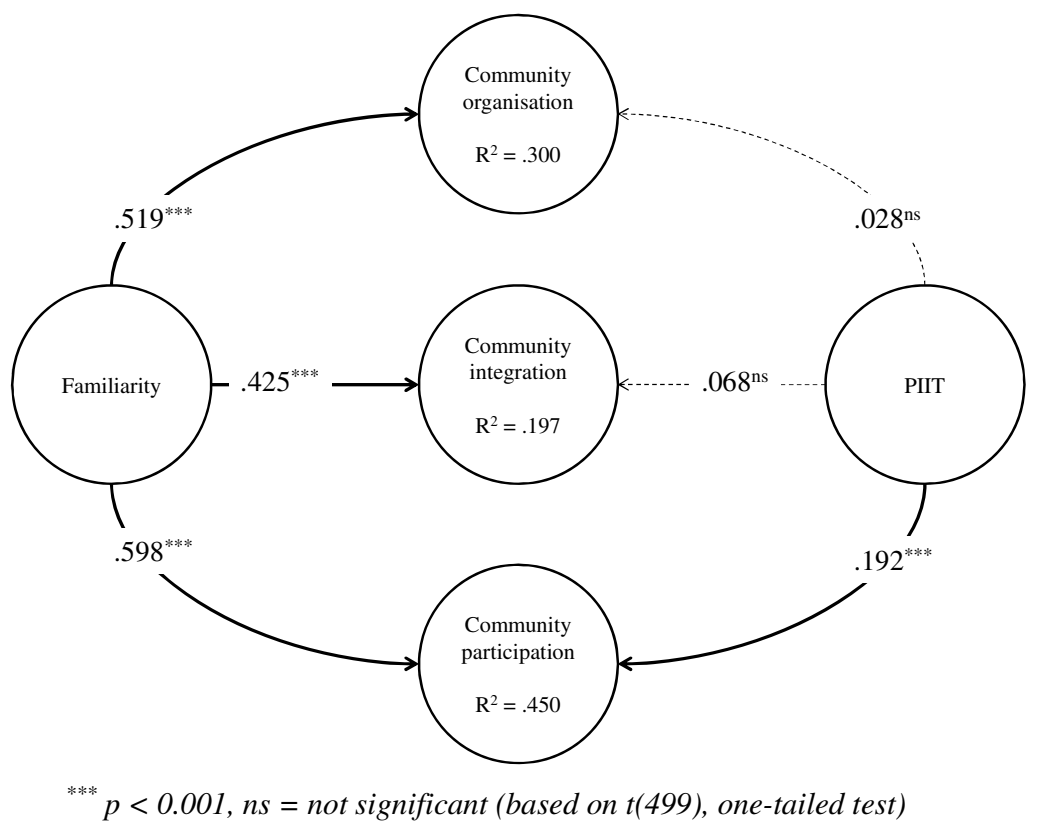

Fig. 2. Structural model. Main effects model. 
The interaction effects were also included, in addition to the main effects model see Figure 3. As in regression analysis, the predictor and moderator variables are multiplied to obtain the interaction terms. According to Chin et al. (2003), product indicators are developed by creating all possible products from the two sets of indicators and the standardising of the product indicators is recommended. However, in the presence of significant interaction terms involving any of the main effects, no direct conclusion can be drawn from these main effects alone [2]. In particular, the interaction effects were of 0.121 -familiarity * PIIT $\rightarrow$ community participation$(\mathrm{p}<0.01)$, and 0.156 - familiarity * PIIT $\rightarrow$ community organisation - $(\mathrm{p}<0.01)$. Hypotheses $\mathrm{H} 3 \mathrm{a}$ and $\mathrm{H} 3 \mathrm{c}$ were supported. Higher PIIT increases the impact of familiarity on community organisation and participation.

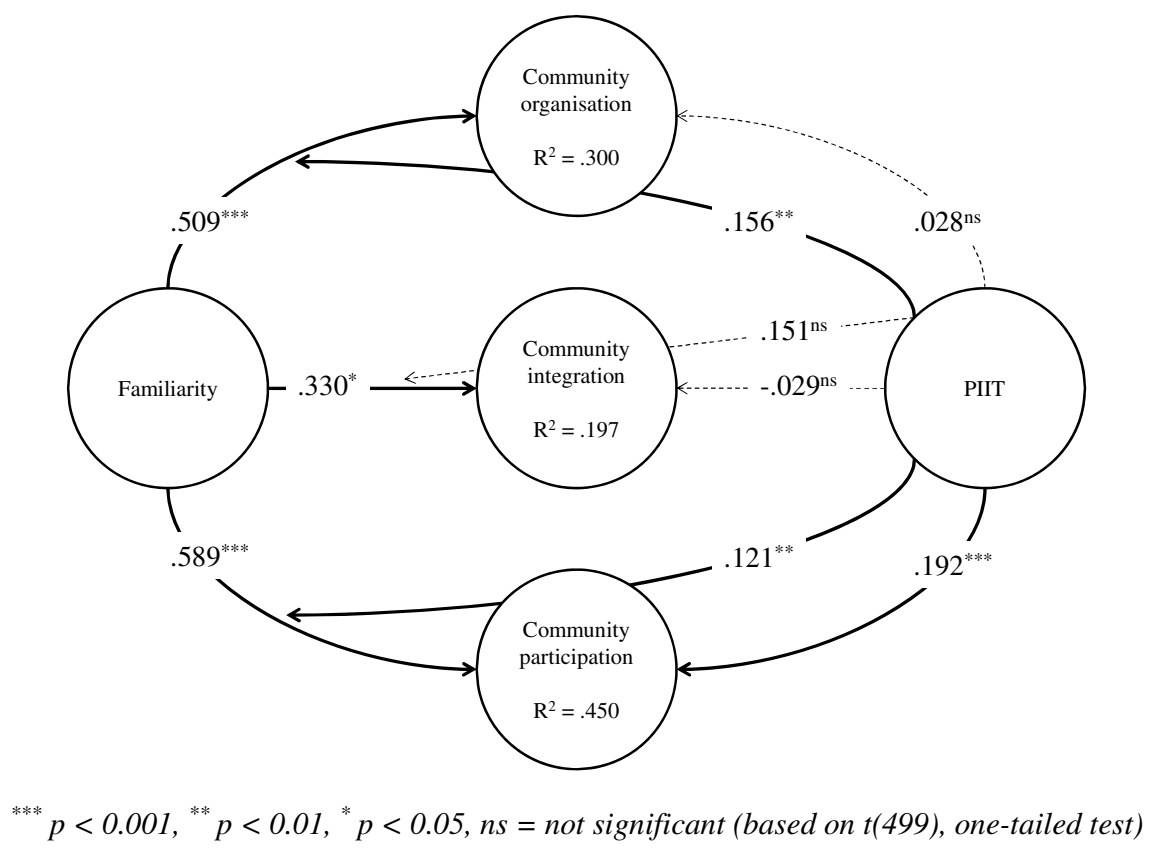

Fig. 3. Structural model. Interaction effects model.

\section{Conclusions}

Our research focused on the association between PIIT, familiarity and PCS by studying the moderating effects of PIIT -i.e., the interaction effects model. We were unaware of previous research that examined interaction effects of familiarity and PIIT on the sense of virtual community and participation. In order to establish a social integration between users and SNSs, this study extended previous research.

In particular, the measurement models were valid, with acceptable convergent and discriminant validity. Our results provided strong support for the arguments that personal differences (i.e., PIIT and familiarity) lead the Tuenti member into developing a growing PCS -by enthusiasm for a community activity and reducing the 
uncertainty of the relationship with it. PIIT directly influences on community participation, and familiarity influences on community participation, integration and organisation. Likewise, higher PIIT increases the impact of familiarity on community organisation and participation.

Community managers will, therefore, take account of familiarity and PIIT to customise their social strategies in order to (a) increase users' enthusiasm in SNSs, and (b) establish involvement and participation in community activities and, consequently, the individual's feelings of identity and attachment to them.

\section{Discussion}

Members with higher levels of PIIT (or willingness of an individual to try out any new Information Technology) (a) tend to be more risk-taking, and (b) are expected to have more positive intentions toward community participation. Innovative members will be selective processors who often rely on a subset of highly available and salient cues in place of detailed elaboration related to community integration or affective commitment. Innovative members will specially try the Tuenti community because it may provide productivity enhancement - even if they do not have a positive attitude towards using it or community integration -.

Likewise, it is suggested that PIIT could be a moderator of familiarity; i.e., users with high personal innovativeness may not be familiarised users. Therefore, to some extent these relationships (between familiarity and PCS) could be influenced by an individual's enthusiasm or keen interest in Information Technology -which has been established as PIIT. We initially proposed that innovative users might be easily persuaded to try the new technology without any elaborated cognitive structure (or familiarity). Contrariwise, PIIT predisposed members to a higher influence of familiarity on community organisation, and participation. Hence, when familiarised members (i.e., with fulfilling routines and procedures for dealing with Tuenti community) are more concerned about Information Technologies (and less deeply engaged in cognitive elaboration), they will thus more inclined to promote accurate mutual aid and empathy. They will tend to be more informal and are more willing to share personal information, thereby (a) achieving greater PCS and (b) resulting in increased opportunities to deepen their knowledge about them.

End-users' familiarity with using SNSs emphasises sense of virtual community and participation. Alternatively, innovative members will apply community features in innovative and novel ways that go beyond the familiarity -enabling them to explore the value potential of SNSs more fully. Accordingly, different members' segments (defined by PIIT) will play an interaction role in affecting the influence of familiarity (in terms of the knowledge members have of an SNS, based on their experience and previous contacts) on the success of community support SNS -i.e., the active mutual exchange and integration of a significant percentage of the community members. These members will progressively overestimate members' feelings of being assisted by the online community in terms of support needs and resources available to the individual -e.g., knowledge and ideas related to mutual interest. Furthermore, increasing PIIT and familiarity can be seen as important initiatives that promote integration and avoid the consideration of competitive SNSs. As Sørebø et al. (2008, 
p.326) note, "an important challenge, for both IS research and practice is to find ways of influencing users to initiate and engage in purposeful behaviour". A community manager should consider how to assist members fostering intrinsic motivation so that they can attain gains in social integration -e.g. novelty, flow, and increased perceived control, or providing community features where innovative members who have provided useful suggestions to other members are identified. In fact, "for individuals with high innovativeness in IT, improving their identity verification in an online community becomes very important" [14, p.848]. Community managers should also focus more on providing expressive and interesting features in SNSs, such as an attractive interface. For instance, as Sánchez-Franco and Roldán (2010, p.1455) concluded, "the influence of aesthetics on feelings of membership, identity, and attachment to a SNS was outweighed in routinisation conditions and personal innovativeness, reinforcing perceived community support". Moreover, these authors concluded that the visual originality itself is essential and inseparable from innovative users. Likewise, members need to be motivated so that they are willing to get familiar with the SNS. In this regard, community managers need to "understand the nature of customer expectations, how these are formed and how they change" (Kotzë and du Plessis, 2003, p193).

The authors recognise some limitations in this research. The model clearly did not include all the relevant variables. Future research should not overlook calculative integration (or commitment); that is, "the state of attachment to a partner cognitively experienced as a realization of the benefits sacrificed and losses incurred if the relationship were to end" [21, p.28]. Secondly, the sample selection process was nonrandom. The selection of the respondents might have been subject to a sample selection bias and therefore, possible refinements in this direction are advisable for future research. In particular, our respondents showed a bias on gender. As Green (1996) evidenced, previous research tends to indicate that female, older, and bettereducated customers participate more in surveys. Therefore, it is difficult to generalise this quasimoderating model and extend the results to other social settings because members from only Tuenti community were surveyed. When studying users of one SNS, future research should exercise caution in generalising the findings to members of another social network site; i.e., certain profiles are more represented on some sites than others.

Acknowledgments. This research was supported by the Junta de Andalucía, Spain (Consejería de Economía, Innovación y Ciencia) -Proyecto de investigación de excelencia SEJ-5801.

\section{References}

1. Agarwal, R., Prasad, J.: A Conceptual and Operational Definition of Personal Innovativeness in the Domain of Information Technology. Information Systems Research 9(2), 204-215 (1998)

2. Aiken, L.S., West, S.G.: Multiple regression: Testing and Interpreting Interactions. Sage Publications, Newbury Park (1991)

3. Alba, J.W., Hutchinson, J.W.: Dimensions of Consumer Expertise. Journal of Consumer Research 13(4), 411-454 (1987) 
4. Baym, N.: Interpreting Soap Operas and Creating Community: Inside an Electronic Fan Culture. In: Keisler, S. (ed.) Culture of the Internet. Lawrence Erlbaum Associates, Mahwah (1997)

5. Bhattacherjee, A., Premkumar, G.: Understanding Changes in Belief and Attitude toward Information Technology Usage: a Theoretical Model and Longitudinal Test. MIS Quarterly 28(2), 229-254 (2004)

6. Bhattacherjee, A.: Understanding Information Systems Continuance: An ExpectationConfirmation Model. MIS Quarterly 25(3), 351-370 (2001)

7. Blanchard, A.L.: Developing a Sense of Virtual Community Measure. CyberPsychology \& Behavior 10(6), 827-830 (2007)

8. Blanchard, A.L.: Testing a Model of Sense of Virtual Community. Computers in Human Behavior 24(5), 2107-2123 (2008)

9. Blanchard, A.L., Markus, L.: Sense of Virtual Community-Maintaining the Experience of Belonging. In: Proceedings of the 35th HICSS Conference, Hawaii, vol. 8 (2002)

10. Blanchard, A.L., Markus, L.: Technology and Community Behavior in Online Environments. In: 3rd International Conference on Communities and Technologies, June 28-30, Michigan State University, Lansing (2007)

11. Casaló, L.V., Flavián Blanco, C., Guinalíu, M.: Antecedents and Effects of Participation in Virtual Brand Communities. In: IADIS International Conference on Web Based Communities, Salamanca, Spain (February 1-10, 2007)

12. Chin, W.W.: The Partial Least Squares Approach to Structural Equation Modelling. In: Marcoulides, G.A. (ed.) Modern Methods for Business Research, pp. 295-336. Lawrence Erlbaum Associates, Inc., Mahwah (1998)

13. Chin, W.W., Marcolin, B.L., Newsted, P.R.: A Partial Least Squares Latent Variable Modeling Approach for Measuring Interaction Effects: Results from a Monte Carlo Simulation Study and an Electronic Mail Emotion/Adoption Study. Information Systems Research 14(2), 189-217 (2003)

14. Chou, Sh-W: Why do Members Contribute Knowledge to Online Communities? Online Information Review (6), 829-854 (2010)

15. Donath, J.S.: Identity and Deception in the Virtual Community. In: Smith, M.A., Kollock, P. (eds.) Communities in Cyberspace, pp. 29-59. Routledge, New York (1999)

16. Ellison, N., Steinfield, C., Lampe, C.: The Benefits of Facebook "Friends": Social Capital and College Students' Use of Online Social Network Sites. Journal of Computer-Mediated Communication 12(4) (2007),

http: / / jcmc.indiana. edu/vol12/issue4/ellison.html

17. Fiske, S.T., Kinder, D.R., Larter, W.M.: The Novice and the Expert: Knowledge-Based Strategies in Political Cognition. Journal of Experimental Social Psychology 19, 381-400 (1983)

18. Flavián, C., Guinalíu, M., Gurrea, R.: The Influence of Familiarity and Usability on Loyalty to Online Journalistic Services: the Role of User Experience. Journal of Retail and Consumer Services 13, 363-375 (2006)

19. Gefen, D.: It is not Enough to be Responsive: the Role of Cooperative Intentions in MRP II Adoption. The Data Base for Advances in Information Systems 31(2), 65-79 (2000)

20. Geyskens, I., Steenkamp, J.-B., Scheer, L.K., Kumar, N.: The Effects of Trust and Interdependence on Relationship Commitment: A Trans-Atlantic Study. International Journal of Research in Marketing 13(4), 303-317 (1996)

21. Gilliland, D.I., Bello, D.C.: Two Sides to Attitudinal Commitment: The Effect of Calculative and Loyalty Commitment on Enforcement Mechanisms in Distribution Channels. Journal of the Academy of Marketing Science 30(1), 24-43 (2002) 
22. Green, K.E.: Sociodemographic Factors and Mail Survey Response. Psychology \& Marketing 13(2), 171-185 (1996)

23. Groth, M.: Customers as Good Soldiers: Examining Citizenship Behaviors in Internet Service Deliveries. Journal of Management 31(1), 7-27 (2005)

24. Henseler, J., Fassott, G.: Testing Moderating Effects in PLS Path Models: An Illustration of Available Procedures. In: Vinzi, E.V., Chin, W.W., Henseler, J., Wang, H. (eds.) Handbook of PLS and Marketing, pp. 713-736. Springer, Berlin (2010)

25. Henseler, J., Ringle, C.M., Sinkovics, R.R.: The Use of Partial Least Squares Path Modeling in International Marketing. Advances in International Marketing 20, 277-319 (2009)

26. Herrero, J., Gracia, E.: Measuring Perceived Community Support: Factorial Structure, Longitudinal Invariance, and Predictive Validity of the PCSQ (Perceived Community Support Questionnaire). Journal of Community Psychology 35(2), 197-217 (2007)

27. Johnson, E.J., Russo, J.E.: Product Familiarity and Learning New Information. Journal of Consumer Research 11, 542-550 (1984)

28. Karahanna, E., Ahuja, M., Srite, M., Galvin, J.: Individual Differences and Relative Advantage: the Case of GSS. Decision Support Systems 32(4), 327-341 (2002)

29. Kotzé, T.G., du Plessis, P.J.: Students as "Co-producers" of Education: A Proposed Model of Student Socialization and Participation at Tertiary Institutions. Quality Assurance in Education 11(4), 186-201 (2003)

30. Lengnick-Hall, C.A., Claycomb, V., Inks, L.W.: From Recipient to Contributor: Examining Customer Roles and Experienced Outcomes. European Journal of Marketing 34(3/4), 359-383 (2000)

31. Lewis, W., Agarwal, R., Sambamurthy, V.: Sources Influence on Beliefs about Information Technology Use: An Empirical Study of Knowledge Workers. MIS Quarterly 27(4), 657-678 (2003)

32. Limayem, M., Khalifa, M., Frini, A.: What Makes Consumers Buy from Internet? A Longitudinal Study of Online Shopping. IEEE Transactions on Systems, Man, and Cybernetics - Part A: Systems and Humans 30(4), 421-432 (2000)

33. Loewenfeld, F.: Brand Communities-Erfolgsfaktoren und Ökonomische Relevanz von Markeneigenschaften. Deutscher Universitäts-Verlag, Wiesbaden (2006)

34. McKenna, K.Y.A., Green, A.S., Gleason, M.E.J.: Relationship Formation on the Internet: What's the Big Attraction? Journal of Social Issues 58(1), 9-31 (2002)

35. McMillan, D.W., Chavis, D.M.: Sense of Community: A Definition and Theory. Journal of Community Psychology 14(1), 6-23 (1986)

36. Mitchell, A.A., Dacin, P.F.: The Assessment of Alternative Measures of Consumer Expertise. Journal of Consumer Research 23, 219-240 (1996)

37. Ringle, C.M., Wende, S., Will, A.: SmartPLS 2.0 (Beta). University of Hamburg: Hamburg, Germany (2005), http: / /www. smartpls. de (accessed March 20, 2008)

38. Roehrich, G.: Consumer Innovativeness: Concepts and Measurements. Journal of Business Research 57(6), 671-677 (2002)

39. Rogers, E.M.: Diffusion of Innovations, 1st edn. Free Press, New York (1962)

40. Rogers, E.M.: Diffusion of Innovations, 4th edn. Free Press, New York (1995)

41. Rogers, E.M.: Diffusion of Innovations, 5th edn. Free Press, New York (2003)

42. Rothaermel, F.T., Sugiyama, S.: Virtual Internet Communities and Commercial Success: Individual and Community-Level Theory Grounded in the Atypical Case of TimeZone. com. Journal of Management 27(3), 297-312 (2001) 
43. Sánchez-Franco, M.J.: The Moderating Effects of Involvement on the Relationships between Satisfaction, Trust and Commitment in E-Banking. Journal of Interactive Marketing 23(3), 247-258 (2009)

44. Sánchez-Franco, M.J., Roldán, J.L.: Expressive Aesthetics to Ease Perceived Community Support: Exploring Personal Innovativeness and Routinised Behaviour as Moderators in Tuenti. Computers in Human Behavior 26(6), 1445-1457 (2010)

45. Sørebø, A.M., Sørebø, Ø., Sein, M.K.: The Influence of User Involvement and Personal Innovativeness on User Behavior. International Journal of Human and Social Sciences 3(5) (2008)

46. Tornatzky, L.G., Fleischer, M., Chakrabarti, A.K.: The Processes of Technological Innovation. Lexington Books. Massachusetts (1990)

47. Tu, C.-H., McIsaac, M.: The Relationship of Social Presence and Interaction in Online Classes. American Journal of Distance Education 16(3), 131-150 (2002)

48. Turner, J.W., Grube, J.A., Meyers, J.: Developing Optimal Match within Communities: An Exploration of CMC Support Communities and Traditional Support. Journal of Communication 51, 231-251 (2001)

49. Wellman, B., Guilia, M.: Net Surfers don't Ride Alone: Virtual Communities as Communities. In: Wellman, B. (ed.) Networks in the global village: Life in contemporary communities. Westview Press, Boulder (1999)

50. Woszczynski, A.B., Roth, P.L., Segars, A.H.: Exploring the Theoretical Foundations of Playfulness in Computer Interactions. Computers in Human Behavior 18(4), 369-388 (2002)

51. Yi, M.Y., Fiedler, K.D., Park, J.S.: Understanding the Role of Individual Innovativeness in the Acceptance of IT-based Innovations: Comparative Analyses of Models and Measures. Decision Sciences 37(3), 393-426 (2006a) 